\title{
Synthesis of ambient pressure dried thermal isolative silica aerogel powder from non-ion exchanged water glass
}

\author{
Steve De Pooter ${ }^{1, *}$, Steven Latré ${ }^{2}$, Frederik Desplentere ${ }^{2}$, David Seveno ${ }^{1}$ \\ 1) Department of Materials Engineering, KU Leuven, Kasteelpark Arenberg 44, B-3001 Leuven, Belgium \\ 2) Materials Technology Cluster, KU Leuven, Campus Brugge, Spoorwegstraat 12, B-8200 Sint-Michiels, Belgium
}

\begin{abstract}
In order to make aerogel available for a wide application range, the synthesis complexity, use of hazardous components and high cost price need to be lowered. In this work, silica aerogel powders were obtained using water glass as a precursor, but without performing ion exchange resulting in a faster and easier synthesis. For this study, 6 and $8 \mathrm{wt} \%$ silica sols were prepared and the difference in properties of the resulting aerogels was investigated. A combined solvent exchange, silylation and washing out of sodium ions was carried out using a hexane:trimethylchlorosilane:isopropylalcohol solution. A molar ratio trimethylchlorosilane/pore water of only 0.11 was used. The resulting hydrophobic organogels were then dried at ambient pressure and temperature. The aerogel powder was finally dried in an oven at $150^{\circ} \mathrm{C}$ to remove the residual moist. No notable shrinkage was observed during and after drying for samples with $8 \mathrm{wt} \%$ silica. The obtained aerogel showed low density of around $100-120 \mathrm{~kg} / \mathrm{m}^{3}$, high porosity of $93-94 \%$, pore volume of $0.6-4.1 \mathrm{~cm}^{3} / \mathrm{g}$, an average pore size of $32-50 \mathrm{~nm}$, and a thermal conductivity of $23-25 \mathrm{~mW} \mathrm{~m}^{-1} \mathrm{~K}^{-1}$, all depending on the weight percentage of silica and $\mathrm{pH}$ of the sol.
\end{abstract}

Key words: Silica aerogel, water glass, solvent exchange, ambient pressure, thermal conductivity

*Corresponding author.

E-mail address: steve.depooter@kuleuven.be (S. De Pooter)

\section{Introduction}

Regarding climate change, buildings are responsible for $40 \%$ of energy consumption and $36 \%$ of $\mathrm{CO}_{2}$ emissions in Europe according to the European Commission [1]. Future buildings have to be constructed according to the highest standards of low energy consumption by 2020, which is difficult to achieve with conventional construction materials [2], [3]. Aerogels are known for their extraordinary properties because of their high porosity (90-99.8\%) and the range of applications is growing. Silica aerogels are obtained with low densities $\left(<0.05 \mathrm{~g} / \mathrm{cm}^{3}\right)$, high specific surface area $\left(>1000 \mathrm{~m}^{2} / \mathrm{g}\right)$, and low thermal conductivity $\left(<20 \mathrm{~mW} \mathrm{~m}^{-1} \mathrm{~K}^{-1}\right)$ [4]. They can then be seen as the perfect candidates to meet these requirements. However the largest limitation was and still is price to apply this materials on a wide scale, especially in low-cost matrices, like cement, plaster or other products in the building industry. Another issue is that for aerogel synthesis, sometimes toxic components e.g. TMOS, high amounts of solvent, high pressures and temperatures are needed, resulting in a not very environmentally friendly and unsustainable material [5]-[9]. A way to overcome these problems is by synthesizing an aerogel out of cheap precursors, without too many washings, high amounts of solvent and hydrophobization agent, and preferably without supercritical drying [10]-[14]. Water glass, an aqueous solution of sodium silicate, is therefore a good precursor choice and can moreover be obtained out of building waste material [15]. Sodium silicate is about four times less expensive than tetraethyl orthosilicate (TEOS), but contains sodium ions and gives less homogeneous gels compared to silica alkoxides [16]. In this study, ambient pressure drying (APD) is preferred to supercritical drying 
$(\mathrm{SCD})$ as it does not require an autoclave, which operates at high pressures and temperatures and limits the sample size to less than its volume.

Homogeneous silica gels from water glass are commonly obtained by first ion exchanging the sodium ions of the latter with hydrogen ions via a cation exchange resin to obtain silicic acid having a $\mathrm{pH}$ typically around 2 [17]-[21]. A base like ammonia or diluted sodium hydroxide is then added to this silicic acid until a pH of 3.5-5 is reached. Silanol groups from the silicic acid bond with each other (condensation) forming siloxane bridges, forming a stable suspension of colloidal solid nanoparticles in water, also called the sol [21], [22]. Gelation then starts as the sol condensates further and more siloxane bridges got formed, resulting in a network. If the silica concentration is above a critical value, the gel remains and coarsens in structure, without precipitation [21]. Some heating can be applied to speed up the gelation. The effect of $\mathrm{pH}$, amount of base, temperature and silica content on the silica gel properties have already been examined by ller [21]. However, there is still no complete understanding of the gelation process. The $\mathrm{pH}$ has a major effect on the structure of the gel network, the thickness of the solid backbone and the pore size distribution. In acidic solution silicic acid polymerizes to extremely small particles and oligomers which connect to each other to form long thin chains as their end groups are most reactive, resulting in a gel network throughout water. In basic solution silica polymerizes to discrete colloidal particles, as the middle part of the oligomers is then the most reactive, grows in size to larger than $4-5 \mathrm{~nm}$ and remains a stable sol. However, The disadvantages of the ion exchange method is the unavoidable presence of residual sodium ions in the low limit, the environmental costs of recovering the ion exchange resin [23] and its unknown impact on the final cost of the material [24]. In case the sodium ions were not exchanged out of the water glass, which is basic in nature having a pH higher than 12 , an acid e.g. hydrochloric or nitric acid needs to be added to neutralize the sodium silicates so that hydrolysis will occur and silanol groups will form [22], [25], [26]. Homogeneous gels can be obtained at a pH below 6 , whether or not a salt (sodium) is present [21]. However, in neutral or alkaline conditions and if the silica sol contains substantial amounts of salts, a white precipitate (rapid coagulation) is formed or in some cases a white opaque gel due to partial precipitation before gelation [21], [27].

Schwertfeger et al. stated that the sol-gel process can be considered as the step where the properties of the final aerogel are determined [28], which is logical as an aerogel is obtained when the wet gel almost does not shrink irreversibly during drying and therefore the same porous structure is maintained. A network built of thin backbones and mesopores $(2-50 \mathrm{~nm})$ poorly conducts heat both through the solid and gas phase, and is therefore desired for good thermal insulation properties [4]. However, a network consisting of thin chains is more likely to collapse, resulting in an irreversible shrunken and collapsed structure, called xerogel [4], [21] with high density, small pore volume and high thermal conductivity. Gels can be aged to allow further polymerization and a stronger network obtained thanks to coarsening. However, there can also occur collapse (syneresis) and air bubble formation, destroying the pore structure. Aging at room temperature takes considerably longer to obtain the same strength and stiffness than when performed at higher temperatures, but it is the safest way and also results in the strongest gels. In the case of aerogel powders, contrary to monoliths, the formation of air bubbles is not a real issue.

A silica aerogel can be obtained out of APD only through surface modification and solvent exchange [8], [9], [29]-[31]. Both procedures make sure that the gel does not collapse when the pore liquid evaporates and leaves the gel during drying at ambient pressure by minimizing the capillary pressure. The surface modification, also called silylation, replaces the silanol groups on the backbone surface with methyl groups, creating a (super)hydrophobic gel. Without this treatment, the gel network would shrink during APD as silanol groups get close to each other, react and form siloxane bridges, resulting in a xerogel. Methyl groups on the other hand, slightly repel each other and induce the spring back effect or reversible shrinkage. However, to make this possible, the pore liquid, in this case water, needs to be exchanged with a new solvent having a low surface tension and allowing the hydrophobization agent to react with the silanol groups. 
Extensive research have already been dedicated to this approach, which in the early protocols [8], [9] required several gel washings, solvent exchanges and high amounts of hydrophobization agent, resulting in a long and expensive process, hampering the synthesis on an industrial scale. Schwertfeger et al. [28] developed a synthesis route using ion exchanged water glass as precursor and reduced the amount of solvent exchanges to only one, which occurred simultaneously during the hydrophobization. Aged silica hydrogels were immersed in hexamethyldisiloxane (HMDSO) and trimethylchlorosilane (TMCS) was added to react with the silanol groups on the backbone and replace them by trimethylsilyl groups with release of hydrochloric acid ( $\mathrm{HCl})$. TMCS reacts also heavily with water to form HMDSO and the latter can react back to TMCS with $\mathrm{HCl}$. This is shown in equations (1) and (2) below:

$$
\begin{gathered}
\mathrm{TMCS}+\equiv \mathrm{Si}-\mathrm{OH} \rightarrow \equiv \mathrm{Si}-\mathrm{O}-\mathrm{Si}\left(\mathrm{CH}_{3}\right)_{3}+\mathrm{HCl} \\
2 \mathrm{TMCS}+\mathrm{H}_{2} \mathrm{O} \rightleftharpoons \mathrm{HMDSO}+2 \mathrm{HCl}
\end{gathered}
$$

The hydrophobic methyl groups help the pore water to go out. A phase separation of superhydrophobic organogel filled with HMDSO floating on a water phase containing acid and unreacted substances got formed. The wet gel could then be easily removed and dried at ambient conditions, without substantial shrinkage and thus aerogel was obtained. However, because high amounts of TMCS and HMDSO were required, Lee et al. [12] replaced the HMDSO with the cheaper Hexane and Isopropyl alcohol (IPA). IPA was added as a transition liquid as it has a polar and nonpolar part and therefore guarantees a more efficient exchange from water (polar) to hexane (nonpolar). After silylation the pores are also mainly filled with HMDSO rather than hexane, which surrounds the gel. A disadvantage of both silylations is that high amounts of the very corrosive $\mathrm{HCl}$ got formed and part remains in the aerogel.

The company JIOS Aerogel patented a co-precursor method [32] in which hydrophobization and solvent exchange occur simultaneously during gelation, also using water glass as precursor, but without prior ion exchange, as most of the sodium ions getting washed out during the solvent exchange. The procedure is almost identical to the one described by Bhagat et al. [13] and allows a fast (5 hours) and cheaper production of aerogel powder. However, this co-precursor method is difficult to control and does not always guarantee repeatability as will be indicated in section 3.5. Furthermore the gel does not get time to age and gain strength. Therefore, especially on industrial scale, a separate gelation and hydrophobization is preferred.

The synthesis route described in here forms a gel out of water glass without prior ion exchange. Furthermore the gels were formed in alkaline conditions and therefore no high amounts of acid were added. The sodium ions and unreacted substances were also not washed out of the aged gels in a separate step like in Kistler's synthesis [25], but during the simultaneous hydrophobization and solvent exchange, following Bhagat [13],[14] and JIOS [32]. This is less time consuming and more sustainable as no extra solvent is needed for washing. The gel is immersed in a silylation solution composed of Hexane:IPA:TMCS, but in a far lower molar ratio TMCS/pore water of 0.11 than Hwang et al. [10] and Lee et al. [12] with ratios of 0.3-0.4 and 0.4, respectively. This would result in a raw materials cost of around $200 \mathrm{EUR} / \mathrm{m}^{3}$, keeping in mind that this cost is the main contribution for any large scale industrial materials manufacturing process. This is extremely low compared to commonly accepted aerogel prices in the range of $2500-5000 \mathrm{EUR} / \mathrm{m}^{3}$ [24]. Organogel filled with mainly HMDSO were finally obtained, and then dried at ambient pressure resulting in aerogel powder. In next samples, TMCS was replaced by HMDSO, as the latter only releases water and neither acid nor base, and therefore no corrosive elements like $\mathrm{HCl}$ [33] remain in the pores. However, HMDSO needs a catalyst e.g. nitric acid to react with the silanol groups. 


\section{Materials and methods}

\subsection{Silica aerogel powder synthesis}

The protocol to synthesize silica aerogel powder is shown as a schematic representation in Fig. 1. Sodium silicate (water glass, $39-40 \%$ silicates in water with 7.80-8.50\% $\mathrm{Na}_{2} \mathrm{O}$ and $25.80-28.50 \% \mathrm{SiO}_{2}$ ) from abcr GmbH (Germany) was used as precursor, TMCS and HMDSO were obtained from SigmaAldrich. Hexane-(n) a.r., IPA and nitric acid $\left(\mathrm{HNO}_{3}, 65 \%\right)$ were ordered from Chem-Lab and $\mathrm{HCl}, 37 \%$ from Fisher Chemical. Water glass was diluted with distilled water until a silica content of 6 and $8 \mathrm{wt} \%$ were obtained under vigorous stirring, but without formation of bubbles. A $3 \mathrm{M} \mathrm{HCl}$ solution was added to this mixture using a syringe pump to ensure repeatability, while stirring slowly, until a pH of 10.55 and 10.85 was reached, for 6 and $8 \mathrm{wt} \% \mathrm{SiO}_{2}$ sols, respectively. Gelation started for both samples and the solution turned light blue. After 30 minutes, a hard gel was obtained and put to age for 24 hours at $22^{\circ} \mathrm{C}$, during which it turned opaque white. The gel was then crushed and immersed in hexane in $5: 3$ volume ratio. IPA in an amount half of the hexane was then added as well as TMCS under low stirring $(<300 \mathrm{rpm})$. A Si:TMS molar ratio of 1:4 was chosen. The reaction was first very exothermic and temperatures over $50^{\circ} \mathrm{C}$ were reached, which dropped down after a few hours. A heater then maintained the temperature at $40^{\circ} \mathrm{C}$. During this process gel is hydrophobized and solvent exchanged at the same time. A clear phase separation could be observed after 5 hours, the gel being filled with hexane and HMDSO, therefore called organogel [4], was floating on a yellow phase, which consisted mostly of the initial pore water, $\mathrm{HCl}$ from the TMCS, IPA, sodium ions. An aerogel powder was obtained by removing this yellow phase and drying the gel first at room temperature for 12 hours and later in an oven at $150^{\circ} \mathrm{C}$ for 3 hours to evaporate the remaining moisture and for a complete spring back effect. This hydrophobization mixture and mechanism was based on the synthesis route of Lee et al. [12], with the major difference that in this recipe a molar ratio TMCS/pore water of only 0.08 and 0.11 was used for the 6 and $8 \mathrm{wt} \% \mathrm{SiO}_{2}$ gels, respectively, while in their recipe this ratio was 0.4 . Furthermore no ion exchange was executed on the water glass prior gelation and therefore a completely different sol gel process was chosen. Later on HMDSO was used instead of TMCS, keeping the Si:TMS molar ratio of 1:4 and catalyzed by $\mathrm{HNO}_{3}$.

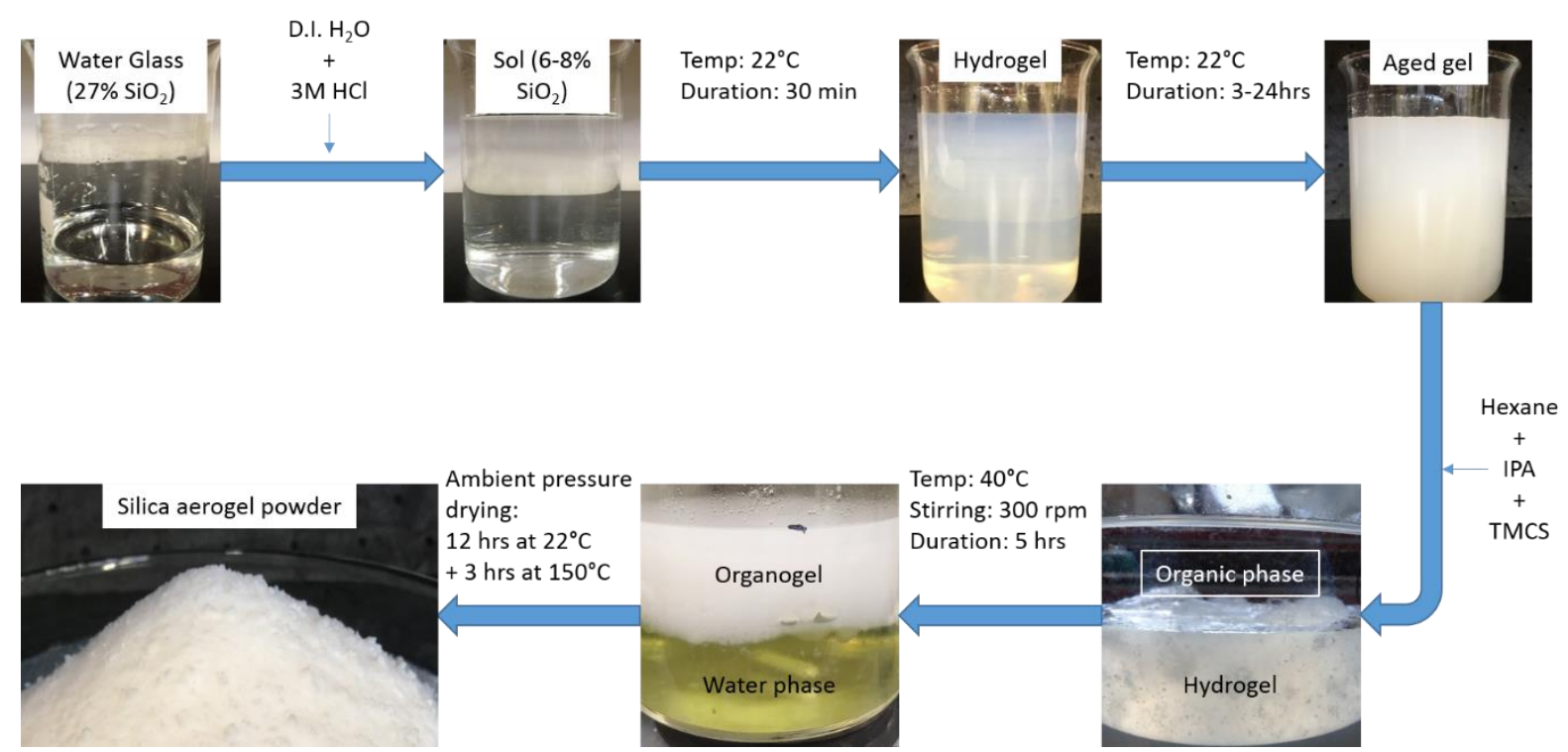

Fig. 1. Schematic representation of the described protocol: silica aerogel powder is synthesized by a simultaneous solvent exchange, hydrophobization and sodium ions removal; organogel is dried at ambient pressure. 


\subsection{Characterization methods}

To measure bulk density of the silica aerogel powder, the mass of known sample volumes was measured (ASTM B212-48). The powder was first dried for 1 hour at $105^{\circ} \mathrm{C}$ and then cooled to room temperature in a desiccator. A quantity of aerogel powder was passed through a $1.0 \mathrm{~mm}$ Hall flow funnel into a $50 \mathrm{ml}$ calibrated cylindrical vessel of brass until it overflows. The excess of powder was then scraped off such that the upper surface of the powder got flat and equaled the level of the border of the vessel. In case of some agglomerates, these were crushed with a thin rod to assure a good flow through the funnel. The mass of the samples were then measured with an accuracy of $0.01 \mathrm{~g}$ and divided by the volume of $50 \mathrm{ml}$ to obtain the bulk density.

The skeletal density was obtained via helium pycnometry using multipycnometer model MVPD160E by Quantachrome Instruments. The largest sample cell of volume $135 \mathrm{~cm}^{3}$ was used. The porosity $\phi_{p}$ and specific pore volume $v_{p}$ are related to both the envelope $\left(\rho_{e}\right)$ and skeletal density $\left(\rho_{s}\right)$ and were calculated using the following equations (3) and (4), respectively:

$$
\begin{aligned}
& \phi_{p}=1-\frac{\rho_{e}}{\rho_{s}} \\
& v_{p}=\frac{1}{\rho_{e}}-\frac{1}{\rho_{s}}
\end{aligned}
$$

The measured bulk density was considered as a good approximation for the envelope density as the aerogel powder was very fine and therefore packed very nicely, giving repeatable results. The shrinkage was estimated as the ratio dry aerogel volume to wet gel volume.

Scanning electron microscope (SEM) images were recorded for all samples using the FEI Nova NanoSEM 450 system. The microscope is equipped with an EDX (energy dispersive X-ray) detector and the EDAX software allowed qualitative and quantitative analysis of elements. This way it could be determined if sodium and chloride ions, from water glass and TMCS respectively, were still present in the aerogel.

The surface area and pore size distribution were determined via nitrogen sorption, using the NOVA $^{\circledR}$-e Series (Model 26) by Quantachrome Instruments, and analyzed with Brunauer-EmmettTeller (BET) [34] and Barret-Joyner-Halenda (BJH) [35] approach, respectively. The range in relative pressure used for BET evaluation was $0.1-0.3$, as the aerogels were expected not to contain a significant amount of micropores [36]. Nitrogen sorption measurements, however, can cause some deformation and collapse of the porous sample, resulting in incorrect results for the average pore diameter obtained via the BJH method. The pore diameter $\left(d_{a v}\right)$ was therefore also calculated (Eq. (5)) from the specific pore volume $\left(v_{p}\right)$ and BET surface area $\left(S_{B E T}\right)$.

$$
d_{a v}=\frac{4 \times v_{p}}{S_{B E T}}
$$

The thermal conductivity was measured by the Lasercomp FOX304 heat flow meter, with a temperature difference of $20^{\circ} \mathrm{C}$ between the hot and cold plate. The hydrophobicity was quantified measuring the static contact angle $(\theta)$ using KSV's CAM200 goniometer, a fully computer controlled instrument. A CCD firewire camera $(512 \times 480)$ with telecentric zoom optics combined with LED based background lighting captures the images. The aerogel powder could not be pressed to pellets, even at high pressures (2000 bar) and was therefore pressed just to obtain a flat surface on which droplets could be made. The shape of the droplets and the measured contact angles will as a result only serve as an indication for the superhydrophobicity. 


\section{Results and discussion}

\subsection{Combined silylation, solvent exchange and washing}

These three mechanisms occurred at the same time and made sure that the gel would not collapse when the pore liquid evaporated out of the gel during drying at ambient pressure by minimizing the capillary pressure. After two hours a clear phase separation was observed, as shown in Fig. 2. The white upper phase contains the organogel filled with HMDSO and surrounded by hexane floating on the yellow water phase, also containing $\mathrm{HCl}$, IPA, sodium ions and unreacted substances. The TMCS reacted very well with the silanol groups, as a phase separation started to get formed already after less than 2 hours and was completed in 5 hours. However the main disadvantage of TMCS is that it releases $\mathrm{HCl}$, which can partially stay inside the aerogel pores. $\mathrm{HCl}$ is very corrosive and is therefore a threat for the production line and storage space [33]. Furthermore traces of this acid in the aerogel could hinder the use of the latter, e.g. in thermal isolative blankets for pipelines. To overcome this problem HMDSO was used instead on some samples. The phase separation took longer, about 5 hours, and a catalyst, in this case $\mathrm{HNO}_{3}$ needed to be added triggering the reaction between $\mathrm{HMDSO}$ and the silanol groups. This gives a clear and colorless pore liquid phase without $\mathrm{HCl}$, as shown on the right in Fig. 2.

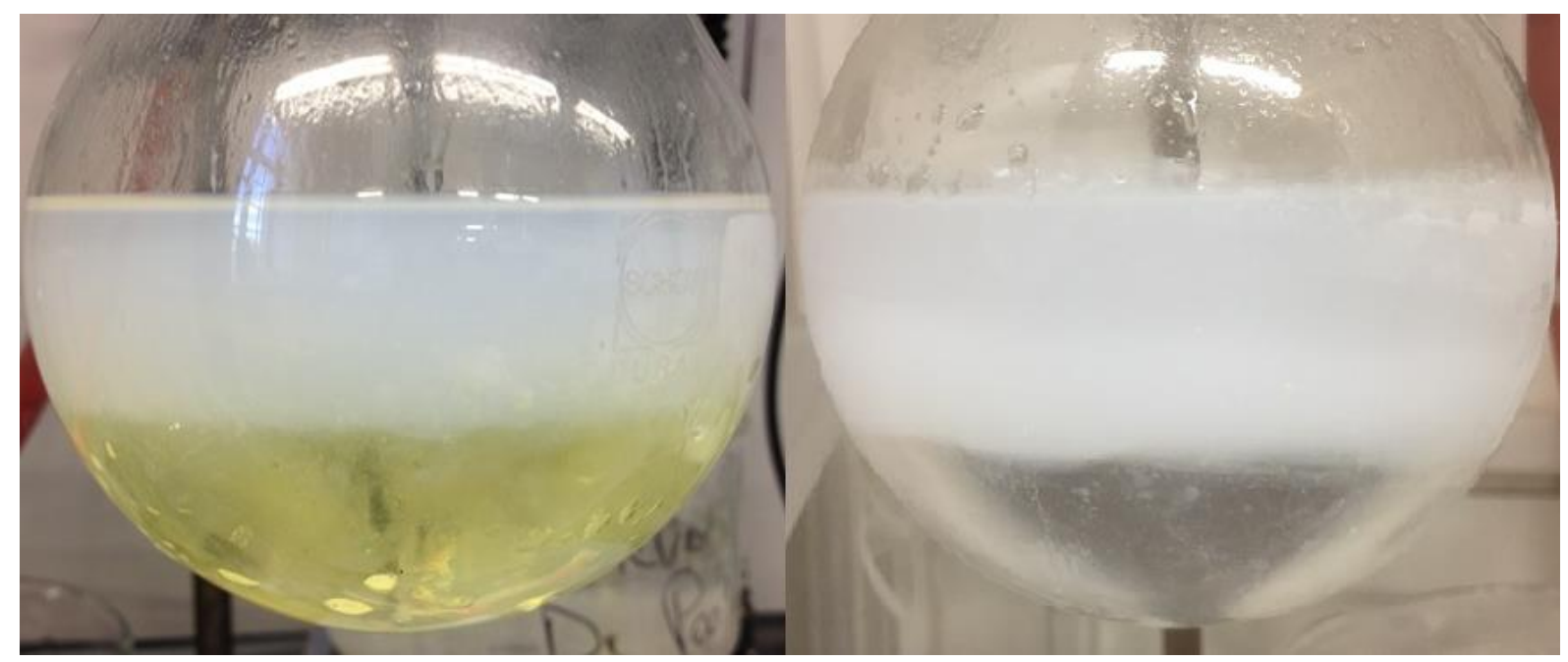

Fig. 2. Left: Phase separation after solvent exchange and silylation with $\mathrm{TMCS}$, resulting in a yellowish water phase with $\mathrm{HCl}$; Right: Phase separation after solvent exchange and silylation with HMDSO, resulting in a colorless water phase without $\mathrm{HCl}$.

\subsection{Scanning electron microscopy and EDX analysis}

The morphology of the aerogel samples are depicted in Fig. 3. The silica aerogels are formed of colloidal particles aggregated into a 3D network. A highly porous structure was observed, however, large openings could also be clearly seen and it was often difficult to determine whether it was a pore, an opening or a crack. A difference between samples with different wt $\% \mathrm{SiO}_{2}$ and $\mathrm{pH}$ could not or only hardly be observed. The $8 \mathrm{wt} \% \mathrm{SiO}_{2}$ aerogel microstructure did not appear denser than the $6 \mathrm{wt} \% \mathrm{SiO}_{2}$ structures, most likely owing to the fact that the latter had shrunken more than the $8 \mathrm{wt} \% \mathrm{SiO}_{2}$, as explained in the following section 3.3. The long aging time before silylation for both samples could also have contributed to more similar structures. 

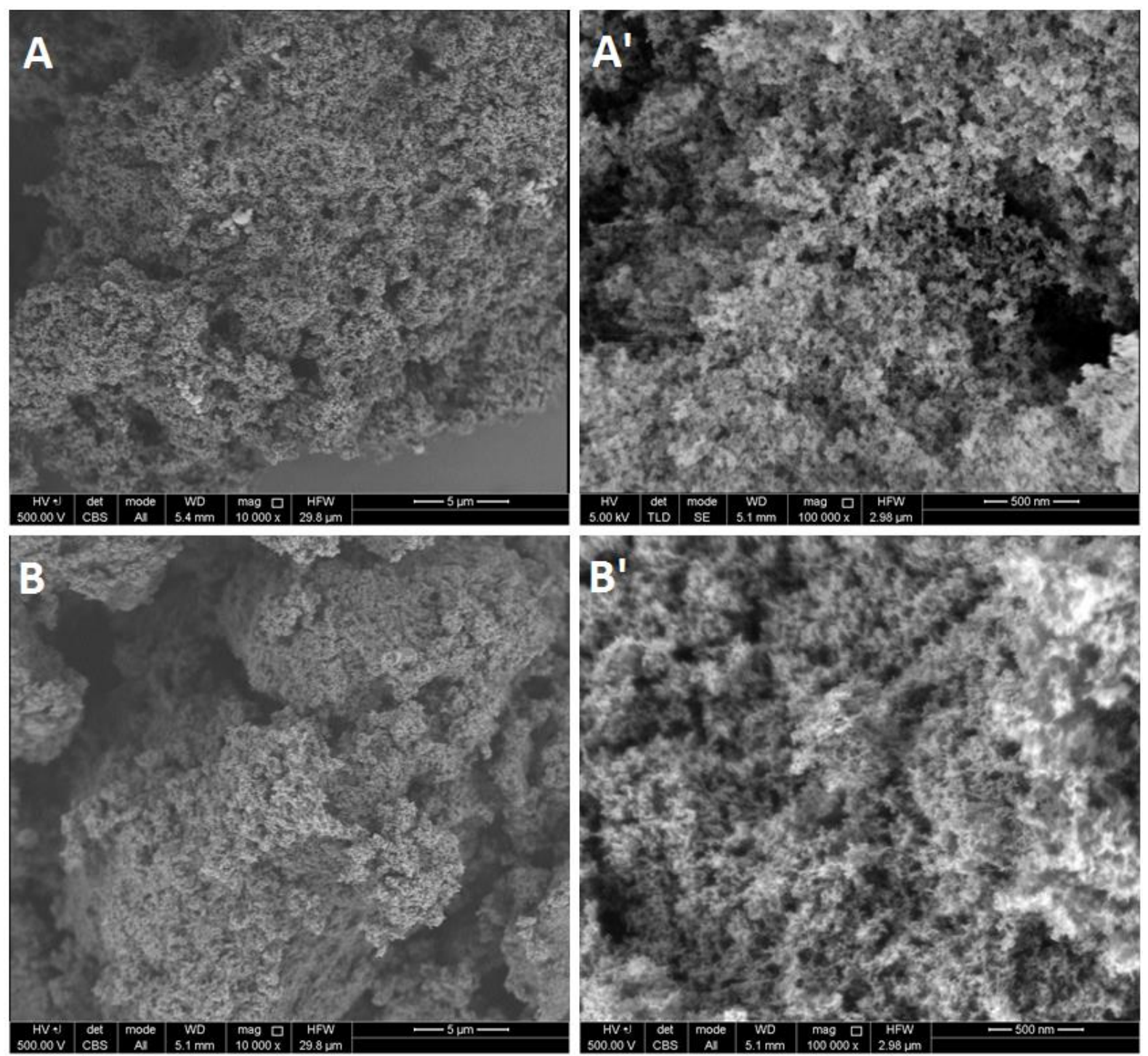

Fig. 3. SEM nanostructure images of the obtained silica aerogel powders at two different magnifications: $8 \mathrm{wt} \% \mathrm{SiO}_{2}-\mathrm{sol} \mathrm{pH}$ $=10.85\left(\mathrm{~A}, \mathrm{~A}^{\prime}\right), 6 \mathrm{wt} \% \mathrm{SiO}_{2}-$ sol $\mathrm{pH}=10.55\left(\mathrm{~B}, \mathrm{~B}^{\prime}\right)$.

When the pore water got pushed out during solvent exchange, sodium ions from the water glass and chloride ions from TMCS also got washed out. Energy dispersive X-ray spectra (EDX) are shown in Fig. 4 for a 8 wt $\% \mathrm{SiO}_{2}$ aerogel sample. Apart from carbon, oxygen and silicon, no other peaks appeared, illustrating there are no more or only negligible amount of sodium and chloride ions present in the aerogel. The carbon peak was expected because of methyl groups on the network, however, part can also be attributed to the carbon black holding the powder. Nevertheless, in the $8 \mathrm{wt} \% \mathrm{SiO}_{2}$ sample, some areas were detected where some white fiber-like structures were present around the aerogel, as can be seen in Fig. 4 . These fibers turned out to be sodium chloride $(\mathrm{NaCl})$. Surprisingly the aerogel in the immediate environment of the $\mathrm{NaCl}$ did not show peaks for sodium or chloride, which occur at 1 and $2.6 \mathrm{keV}$, respectively. It can be concluded that the ions got washed out of the pores and in case a part remains around the gel, it forms solid $\mathrm{NaCl}$ structure after drying. It only occurred for 8 wt $\% \mathrm{SiO}_{2}$ aerogel samples, most likely because of the higher amount water glass and TMCS, resulting in more ions, and can be washed out with deionized water. 

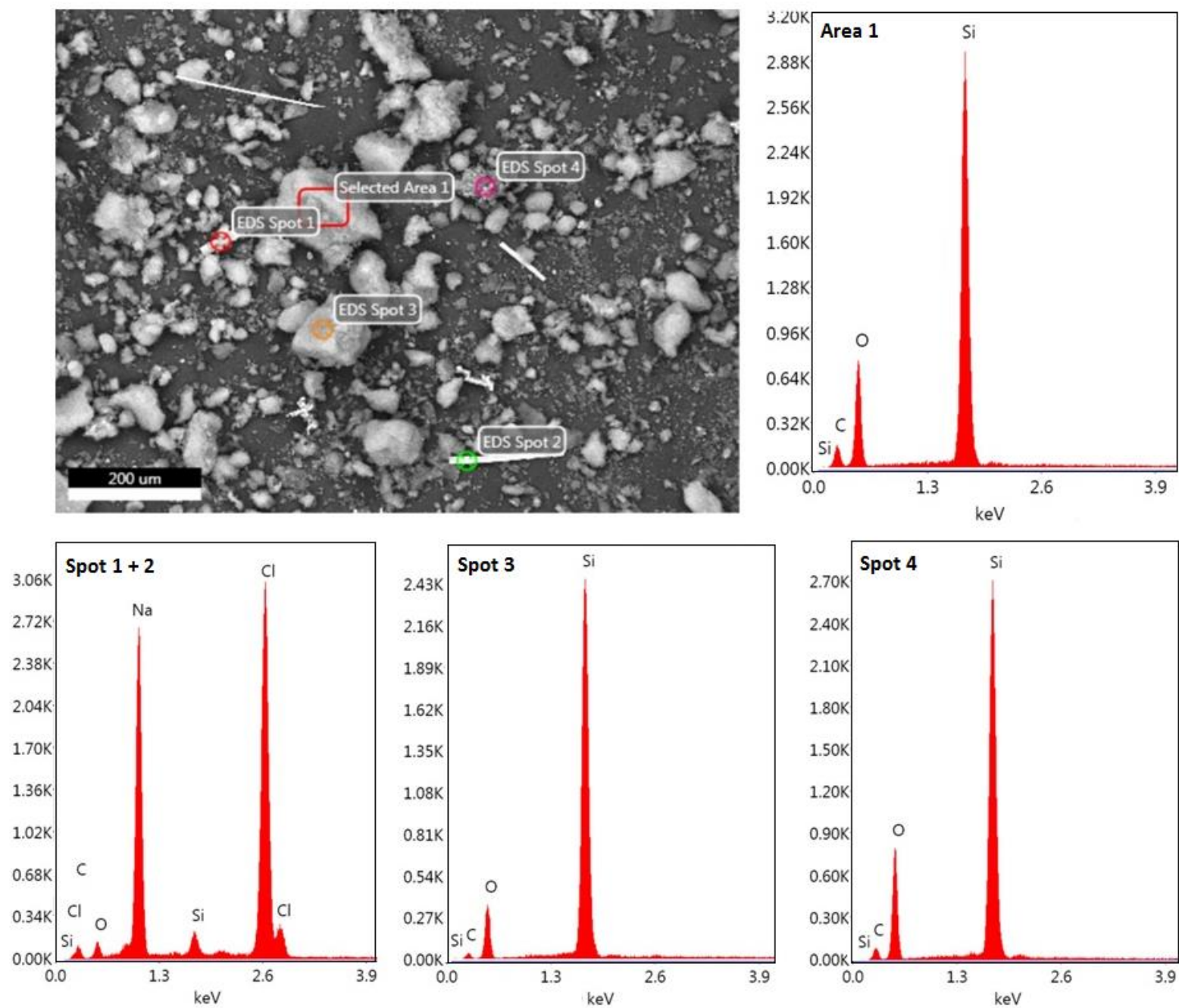

Fig. 4. EDS spectra for the $8 \mathrm{wt} \% \mathrm{SiO}_{2}$ aerogel sample. The white fibers/sticks are (mainly) sodium chloride.

\subsection{Shrinkage, density, porosity and pore volume (calculated)}

After removal of the exchanged pore water phase, the wet gel started to dry immediately at room temperature and the outer surface started to turn opaque white very fast and became powdery. No visible shrinkage was observed for the $8 \mathrm{wt} \% \mathrm{SiO}_{2}$ gels and the resulting powders were very fine and not clustered. The fact that the gel practically did not shrink means that the combined silylation and solvent exchange was effective, but also that the network was strong enough to withstand the capillary pressures during drying. The reason for the latter is that $8 \mathrm{wt} \% \mathrm{SiO}_{2}$ was used, gelation occurred at a pH of 10.85 and a decent aging time was granted to it. Compared to 6 wt\%, a higher weight percentage of silica basically means that there is more material and basic conditions ( $\mathrm{pH} 7-11$ ) give rise to bigger particles and as a result, a thicker structure can be formed. Aging assured a stronger connection between the particles of the network. Gels with $6 \mathrm{wt} \%$ silica were also made, following the same recipe, except for the molar ratio TMCS/pore water, which was only 0.08 . Although the phase separation was also successful, volume shrinkage of $36-48 \%$ was observed, most likely because of the lower silica content which results in a thinner solid backbone as well as the very low TMCS/pore water ratio. The bulk density for aerogel samples with $8 \mathrm{wt} \%$ Silica content was around $0.12 \mathrm{~g} / \mathrm{cm}^{3}$ and the porosity calculated form the bulk and skeletal densities was $94 \%$, while for the $6 \mathrm{wt} \%$ samples it was $0.11 \mathrm{~g} / \mathrm{cm}^{3}$ and $93 \%$, respectively. 
Table 1

Aerogel properties determined via powder volume measurements and helium pycnometry

\begin{tabular}{|cccccccc|}
\hline Sample no. & wt\% $\mathrm{SiO}_{2}$ & Sol pH & $\begin{array}{c}\text { Shrinkage } \\
(\%)\end{array}$ & $\begin{array}{c}\text { Bulk density } \\
\left(\mathrm{g} / \mathrm{cm}^{3}\right)\end{array}$ & $\begin{array}{c}\text { Skeletal density } \\
\left(\mathrm{g} / \mathrm{cm}^{3}\right)\end{array}$ & $\begin{array}{c}\text { Calculated } \\
\text { porosity }(\%)\end{array}$ & $\begin{array}{c}\text { Calculated pore } \\
\text { volume }\left(\mathrm{cm}^{3} / \mathrm{g}\right)\end{array}$ \\
\hline 1 & 8 & 10.85 & 0.5 & 0.120 & 1.68 & 93 & 7.74 \\
2 & 6 & 10.55 & 48 & 0.114 & 1.73 & 93 & 8.16 \\
\hline
\end{tabular}

\subsection{Nitrogen sorption, specific surface area, pore size distribution and pore volume (measured)}

Sorption isotherms are shown in Fig. 5 and have a type IV shape, with the characteristic hysteresis, associated with capillary condensation and typical for silica aerogel [37]. However, there is no limited gas uptake in the higher $\mathrm{p} / \mathrm{p}_{0}$ range and the hysteresis adsorption and desorption branches go only slightly up over a wide $p / p_{0}$ range, except in the end. The type of hysteresis loop for the $8 w t \%$ $\mathrm{SiO}_{2}$ aerogels is therefore closer to $\mathrm{H} 3$, while the one for the $6 \mathrm{wt} \% \mathrm{SiO}_{2}$ samples resembles more $\mathrm{H} 2$, which is more typical for silica gels. According to IUPAC, the type H3 hysteresis is associated with aggregates of plate-like particles, giving rise to slit-shape pores [37]. Such structure could result from partial precipitation that occurred before gel formation. The isotherm also indicates the presence of micropores and a low (external) specific surface area because of the steep increase at lower relative pressures and the very small slope in the intermediate range, respectively [36]. The fact that the hysteresis loop occurs in the higher relative pressure range and that the branches are only slightly parallel and not vertical for the $8 \mathrm{wt} \% \mathrm{SiO}_{2}$ aerogel, indicates a rather wide pore size distribution of large mesopores [36]. The hysteresis loop of the $6 \mathrm{wt} \% \mathrm{SiO}_{2}$ aerogel has more vertical and parallel branches, therefore a narrower pore size distribution of mesopores is expected. This is also observed in Fig. 6 in which the pore size distribution was determined using the BJH method. The peak for the 8 $\mathrm{wt} \% \mathrm{SiO}_{2}$ powder is wider than of the $6 \mathrm{wt} \% \mathrm{SiO}_{2}$, indicating a most frequent pore diameter of around $50 \mathrm{~nm}$ and $33 \mathrm{~nm}$, respectively, and with calculated pore diameter of 100 and $76 \mathrm{~nm}$, respectively. A significant difference in cumulative pore volume was measured for the 8 and $6 \mathrm{wt} \% \mathrm{SiO}_{2}$ samples, 0.64 versus $2.71 \mathrm{~cm}^{3} / \mathrm{g}$, respectively. The $8 \mathrm{wt} \% \mathrm{SiO}_{2}$ aerogel samples had an average BET surface area of $318 \mathrm{~m}^{2} / \mathrm{g}$. This low surface area could be due to the presence of big colloidal particles aggregated in plate-like structures. It should be noted that the specific surface area of a porous sample, like an aerogel, is not defined by the porosity but only by the particle size [21]. The $6 \mathrm{wt} \% \mathrm{SiO}_{2}$ samples had an average surface area of $431 \mathrm{~m}^{2} / \mathrm{g}$. A high surface area was however not an aim in this work, as it is not directly related to the thermal conductivity (Section 3.5).

Table 2

Aerogel properties determined via nitrogen physisorption

\begin{tabular}{|ccccccc|}
\hline Sample no. & wt\% $\mathrm{SiO}_{2}$ & Sol pH & $\begin{array}{c}\text { BET Surface } \\
\text { Area }\left(\mathrm{m}^{2} / \mathrm{g}\right)\end{array}$ & $\begin{array}{c}\text { Pore Volume } \\
\left(\mathrm{cm}^{3} / \mathrm{g}\right)\end{array}$ & $\begin{array}{c}\text { Most Frequent Pore } \\
\text { Diameter }(\mathrm{nm})\end{array}$ & $\begin{array}{c}\text { Calculated Average Pore } \\
\text { Diameter }(\mathrm{nm})\end{array}$ \\
\hline 1 & 8 & 10.85 & 318 & 0.64 & 50 & 100 \\
2 & 6 & 10.55 & 431 & 2.71 & 33 & 76 \\
\hline
\end{tabular}



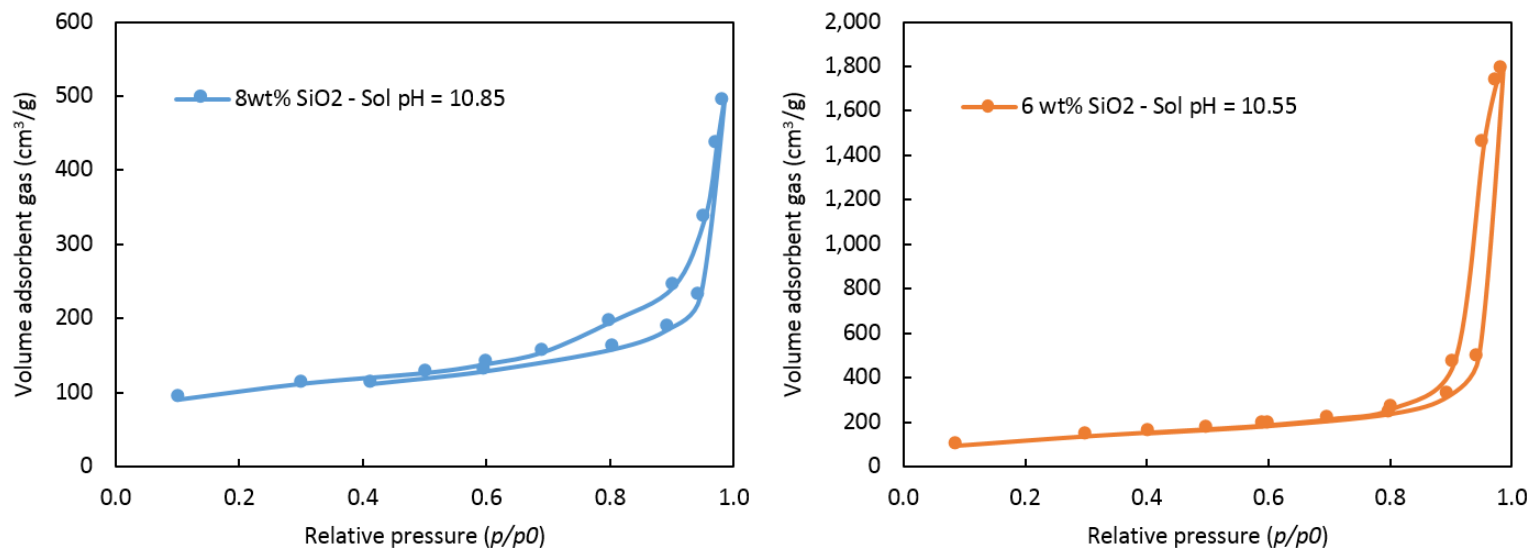

Fig. 5. $\mathrm{BJH}$ isotherms for 8 (left) and 6 (right) $\mathrm{wt} \% \mathrm{SiO}_{2}$ aerogel samples; the sol pH was 10.85 and 10.55, respectively.
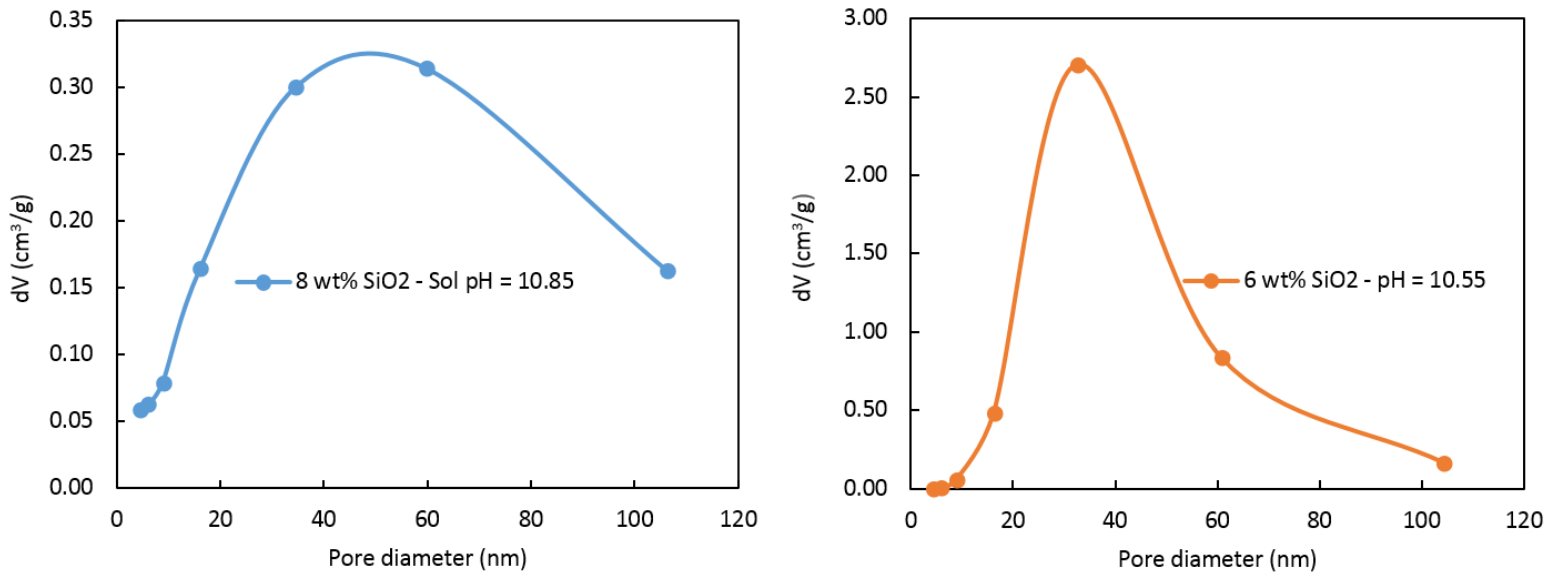

Fig. 6. BJH desorption pore size distributions for 8 (left) and 6 (right) wt\% $\mathrm{SiO}_{2}$ aerogel samples; the sol pH was 10.85 and 10.55 , respectively. An automatic line was fitted through the data points to enhance readability.

\subsection{Thermal conductivity}

Three bags of JIOS AeroVa ${ }^{\circledR}$ aerogel powder were obtained via a Belgian company (not named due to confidentiality) and from each bag two samples were tested for thermal conductivity by the heat flow meter, as shown in Table 3. An average thermal conductivity of $22.2 \mathrm{~mW} \mathrm{~m}^{-1} \mathrm{~K}^{-1}$, with a deviation of 1.4, was measured. The minimum and maximum values were 20.9 and $24.3 \mathrm{~mW} \mathrm{~m}^{-1} \mathrm{~K}^{-1}$, respectively.

Table 3

Measured thermal conductivities for $\mathrm{JIOS}_{\text {AeroVa }}{ }^{\circledR}$ aerogel powder

\begin{tabular}{|c|c|c|}
\hline \multicolumn{2}{|c|}{ JIOS AeroVa ${ }^{\circledR}$ aerogel powder } & $\begin{array}{c}\text { Thermal conductivity } \\
\left(\mathrm{mW} \mathrm{m}^{-1} \mathrm{~K}^{-1}\right)\end{array}$ \\
\hline Bag 1 & Sample 1 & 21.4 \\
& Sample 2 & 22.1 \\
\hline Bag 2 & Sample 3 & 23.3 \\
& Sample 4 & 20.9 \\
\hline Bag 3 & Sample 5 & 20.9 \\
& Sample 6 & 24.3 \\
\hline \multicolumn{2}{|c|}{ Average } & 22.2 \\
& St. deviation & 1.4 \\
\hline
\end{tabular}


These measured thermal conductivities are not entirely in range with the datasheets of JIOS, which depict a range of $17-22 \mathrm{~mW} \mathrm{~m}^{-1} \mathrm{~K}^{-1}$. This can be of course explained by the fact that a different apparatus was used to measure the conductivity. The deviation can however be clearly observed. The values in Table 3 will be used as a reference to compare with the thermal conductivities of the aerogels obtained by the recipe described in this paper, as the same heat flow meter was used.

The aerogels powders obtained from $8 \mathrm{wt} \%$ silica water glass had a thermal conductivity of 25.4 $\mathrm{mW} \mathrm{m} \mathrm{K}^{-1} \mathrm{~K}^{-1}$, slightly lower than the one of air, which is $26 \mathrm{~mW} \mathrm{~m}^{-1} \mathrm{~K}^{-1}\left(25^{\circ} \mathrm{C}, 1 \mathrm{~atm}\right)$, and with a deviation of only 0.1 compared to 1.4 for JIOS samples. The aerogel obtained by Lee et al. [12], [38], which was also made of $8 \mathrm{wt} \%$ silica water glass but ion exchanged, had a thermal conductivity of $\pm 25 \mathrm{~mW} \mathrm{~m}^{-1}$ $\mathrm{K}^{-1}$ (deviation not known). This proves that ion exchange is not necessary to obtain strongly thermal isolative aerogel powder, even when the gelation and silylation occur separately and therefore no coprecursor method is used as for the JIOS powder. Lowering the silica content to $6 \mathrm{wt} \%$ resulted in a conductivity of only $23.4 \mathrm{~mW} \mathrm{~m}^{-1} \mathrm{~K}^{-1}$, keeping the same volume ratios for the hexane, TMCS and IPA, but a molar ratio TMCS/pore water of only 0.08 . A lower weight percentage of silica generally results in thinner backbones, which on their turn conduct less heat. The thermal conductivity is also related to the pore size distribution and pore volume. In case of the $8 \mathrm{wt} \% \mathrm{SiO}_{2}$ aerogels a most frequent pore size was $50 \mathrm{~nm}$, which is still for good thermal insulation properties, although it is on the border of the meso-macroporosity range. For the $6 \mathrm{wt} \%$ the most frequent pore size was $33 \mathrm{~nm}$ and the distribution was narrower, which proved to be better for thermal insulation properties. However a sample with almost the same pore radius, namely $55 \mathrm{~nm}$, had a thermal conductivity of $46.9 \mathrm{~mW} \mathrm{~m}^{-1} \mathrm{~K}^{-1}$, but a pore volume of only $0.41 \mathrm{cc} / \mathrm{g}$, showing the importance of high pore volume. The shape of the physisorption isotherm and hysteresis loop could indicate aggregates of plate-like particles with slit-shapes pores, as explained above. Such pores are not ideal for thermal insulation (Knudsen-effect) and furthermore make it more difficult to measure accurate pore diameters. There is no direct relation between the $\mathrm{BET}$ and thermal conductivity values. This can be demonstrated by the result of a $6 \mathrm{wt} \% \mathrm{SiO}_{2}$ xerogel, obtained by using the same recipe, except for a 1-hour aging time at $65^{\circ} \mathrm{C}$, complete crushing of the gel before silylation under high stirring and a 1:1 volume ratio for hexane:IPA. This sample had a specific surface area of $1032 \mathrm{~m}^{2} / \mathrm{g}$, but a thermal conductivity of $37.9 \mathrm{~mW} \mathrm{~m}^{-1} \mathrm{~K}^{-1}$. However, for mesoand macropores, the average pore size of the aerogel is often estimated by its BET specific surface area and the specific pore volume from the envelope and skeletal density. Therefore, as thermal conductivity depends on the average pore size, the BET surface area has also an influence.

Table 4

Thermal conductivities of synthesized aerogel powders

\begin{tabular}{|cccc|}
\hline Sample no. & wt\% SiO2 & Sol pH & $\begin{array}{c}\text { Thermal } \\
\text { Conductivity } \\
\left(\mathrm{mW} \mathrm{m}^{-1} \mathrm{~K}^{-1}\right)\end{array}$ \\
\hline 1 & 8 & 10.85 & 25.4 \\
2 & 6 & 10.55 & 23.4 \\
\hline
\end{tabular}

\subsection{Hydrophobicity}

The hydrophobicity of the aerogel powders were quantified by placing water droplets on a flat surface and measuring the contact angle. The 8 and $6 \mathrm{wt} \% \mathrm{SiO}_{2}$ samples demonstrated similar wetting behavior and had almost the same average contact angle, $143^{\circ}$ and $145^{\circ}$ respectively, as shown in Fig. 7. By slightly tilting the platform, the droplets rolled of the aerogel powder and "liquid marbles" were formed, which was also observed in other work [39]. The superhydrophobic character of the obtained aerogels is therefore confirmed and serves as an indirect evidence that the silylation process was effective. The aerogel's superhydrophobic behavior can be beneficial in certain applications, e.g. in thermal isolative blankets around pipelines to resist the ingress of moisture and as a result prevent 
the development of corrosion [40]. On the other hand, there is a possible difficulty in mixing these aerogel particles in water based slurries, e.g. plaster or cement [2], [41]. In this work, however, the gel needed to be made superhydrophobic in order to be able to dry at ambient pressure, without too much collapse of the original gel structure.

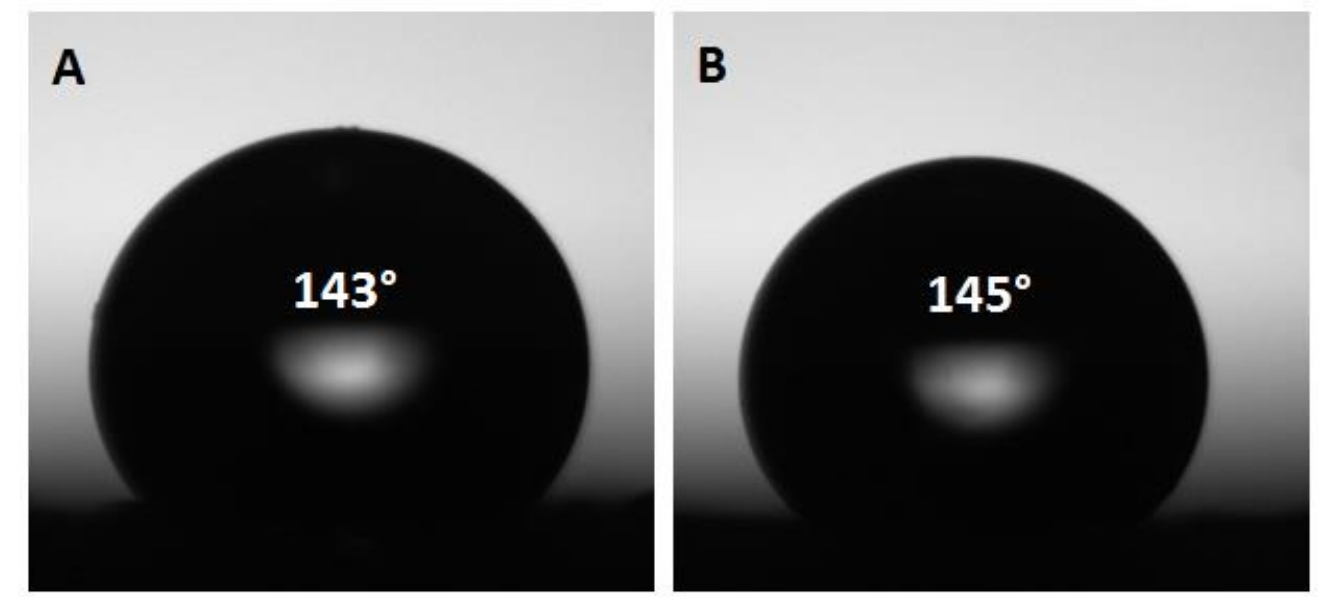

Fig. 7. Contact angles obtained by making water droplets on a flat surface of aerogel powder for $8 \mathrm{wt} \% \mathrm{SiO}_{2}(\mathrm{~A})$ and $6 \mathrm{wt} \%$ $\mathrm{SiO}_{2}$ (B).

\subsection{Summary results and suggested improvements}

An overview of the properties of the aerogels obtained using the recipe described in this paper for both the 6 and $8 \mathrm{wt} \% \mathrm{SiO}_{2}$ samples, are summarized in Table 5 below.

Table 5

Summary of the properties for the obtained aerogel powders

\begin{tabular}{|cccccccccc|}
\hline $\begin{array}{c}\text { Sample } \\
\text { no. }\end{array}$ & $\begin{array}{c}\mathrm{wt} \% \\
\mathrm{SiO}_{2}\end{array}$ & $\begin{array}{c}\mathrm{Sol} \\
\mathrm{pH}\end{array}$ & $\begin{array}{c}\text { Bulk } \\
\text { density } \\
\left(\mathrm{g} / \mathrm{cm}^{3}\right)\end{array}$ & $\begin{array}{c}\text { Porosity } \\
(\%)\end{array}$ & $\begin{array}{c}\text { Calculated } \\
\text { Pore Volume } \\
\left(\mathrm{cm}^{3} / \mathrm{g}\right)\end{array}$ & $\begin{array}{c}\text { Measured } \\
\text { Pore Volume } \\
\left(\mathrm{cm}^{3} / \mathrm{g}\right)\end{array}$ & $\begin{array}{c}\text { BET Surface } \\
\text { Area }\left(\mathrm{m}^{2} / \mathrm{g}\right)\end{array}$ & $\begin{array}{c}\text { Average Pore } \\
\text { Diameter* } \\
(\mathrm{nm})\end{array}$ & $\begin{array}{c}\text { Thermal } \\
\text { Conductivity } \\
\left(\mathrm{mW} \mathrm{m}^{-1} \mathrm{~K}^{-1}\right)\end{array}$ \\
\hline 1 & 8 & 10.85 & 0.120 & 93 & 7.74 & $0.4-0.6$ & 310 & 100 & 25.4 \\
2 & 6 & 10.55 & 0.114 & 93 & 8.16 & 2.71 & 431 & 76 & 23.4 \\
3 & 6 & 10.36 & 0.113 & 93 & 8.25 & 4.1 & 380 & 87 & 18.7 \\
\hline
\end{tabular}

*Calculated

The results described in this paper show that this recipe can deliver aerogels with good properties, especially a low thermal conductivity compared to literature [42]-[45]. However, there is still a need for optimization in repeatability in case extremely low thermal conductivities $\left(<20 \mathrm{~mW} \mathrm{~m}^{-}\right.$ ${ }^{1} \mathrm{~K}^{-1}$ ) have to be obtained. The properties of the final aerogel are mainly determined by the sol-gel process [28], if the silylation and solvent exchange are effective. Thus the wet gel should already have the optimal pore size distribution and network. However, as very low molar ratios TMCS/pore water $(0.08-0.11)$ were used, some higher amounts of TMCS can be used, especially in case of $6 \mathrm{wt} \% \mathrm{SiO}_{2}$ gels where more pore water is present, making the hydrophobization more difficult. For the gel itself, a more homogeneous, continuous and mesoporous network with a thinner backbone is desired. As explained previously, water glass (not ion exchanged) has a high $\mathrm{pH}$ and needs to be partially neutralized to induce gelation [21], while a lower $\mathrm{pH}$ leads to a more homogeneous gel with smaller particles and smaller pores. Therefore a sol pH lower than 10.8 is desired. This can be achieved in two ways, either starting with a more diluted water glass solution and thus a lower wt $\% \mathrm{SiO}_{2}$ or by adding more catalyst (acid) under high stirring. Therefore a $6 \mathrm{wt} \% \mathrm{SiO}_{2}$ sol with a pH of 10.36 was prepared and the resulting gel was treated according to the same protocol, except for an extended drying of 24 hours at $150^{\circ} \mathrm{C}$. This aerogel had a bulk density of $0.113 \mathrm{~g} / \mathrm{cm}^{3}$, a porosity of $93 \%$, a calculated and 
measured pore volume of respectively 8.25 and $4.1 \mathrm{~cm}^{3} / \mathrm{g}$, a BET surface area of $380 \mathrm{~m}^{2} / \mathrm{g}$, a calculated pore diameter of $87 \mathrm{~nm}$, and a thermal conductivity of only $18.7 \mathrm{~mW} \mathrm{~m}^{-1} \mathrm{~K}^{-1}$. Apart from the significantly higher pore volume and lower thermal conductivity, this sample had approximately the same characteristics as the original $6 \mathrm{wt} \% \mathrm{SiO}_{2}$ aerogel sample described in this article. The need for the longer drying is still unsure and needs to be further investigated. This aerogel was however impossible to repeat successfully so far. The $\mathrm{pH}$ can be lowered to more neutral conditions if a higher amount of acid is poured faster to the diluted water glass solution, as $\mathrm{pH}$ goes slightly up during the process. For acidic conditions, the catalyst should be added as fast as possible, after which the stirring should only last for a short while, e.g. a minute. Aging can be done at a certain temperature, higher than $25^{\circ} \mathrm{C}$, e.g. $65^{\circ} \mathrm{C}$ and for a shorter time. This of course results in a more traditional silica gelation process as was described in the introduction.

\section{Conclusion}

A synthesis protocol for silica aerogel powder was designed using water glass without the need for ion exchange or high amounts of neutralizing acid, separate washings, high amounts of solvent and expensive silylation agents. The removal of sodium ions, solvent exchange and hydrophobization occurred simultaneously, resulting in a clear phase separation. Furthermore the molar ratio TMCS/water was kept to a maximum of only 0.11 . All this made the process fairly simple, more sustainable and cheaper than more conventional methods. Samples with $8 \mathrm{wt} \%$ silica were repeatable and had a density around $0.1 \mathrm{~g} / \mathrm{cm}^{3}$, porosity of $94 \%$, pore volume of $0.64 \mathrm{~cm}^{3} / \mathrm{g}$, average pore diameter of $50 \mathrm{~nm}$, BET surface area of $310 \mathrm{~m}^{2} / \mathrm{g}$, a contact angle of $144^{\circ}$ and a thermal conductivity of $25.4 \mathrm{~mW} \mathrm{~m}^{-1} \mathrm{~K}^{-1}$. No real shrinkage was observed as the volume of dry powders was practically the same as of the wet gel. Starting from a $6 \mathrm{wt} \% \mathrm{SiO}_{2}$ sol with a pH of 10.55, keeping the same molar and volume ratios of solvent and silylating agent, resulted in an aerogel powder with a thermal conductivity of $23.4 \mathrm{~mW} \mathrm{~m}^{-1} \mathrm{~K}^{-1}$. Repeating this with a sol pH of 10.36, an aerogel was obtained having a thermal conductivity of $18.7 \mathrm{~mW} \mathrm{~m}^{-1} \mathrm{~K}^{-1}$. However, the latter sample was difficult to repeat as precipitation occurs before the gelation causing a less homogeneous gel. Some higher amounts acid may be required to overcome this precipitation issue. Furthermore extra silylating agent could be added to prevent shrinkage more effectively as more water is present in the $6 \mathrm{wt} \% \mathrm{SiO}_{2}$ gels. The silylation in this protocol was also successful with HMDSO instead of TMCS in order to avoid formation of corrosive $\mathrm{HCl}$ inside the pores. The combination of using a cheap precursor water glass, which can be recovered out of building wastes, without separate ion exchange, low amounts of solvent and hydrophobization agent, and ambient pressure drying makes this aerogel powder more sustainable, and more suitable for an industrial scale production.

\section{Acknowledgements}

The authors would like to acknowledge the support of the agency Flanders Innovation \& Entrepreneurship (VLAIO) in the framework of a Baekeland project (IWT 150713), Tom Van der Donck, from the department Materials Engineering (MTM) of KU Leuven for performing the scanning electron microscope (SEM) images and energy dispersive X-ray (EDX) scans, and dr. Anja Vananroye from the Soft Matter, Rheology and Technology cluster in the Chemical Engineering Department (CIT) of KU Leuven for providing the CAM200 goniometer.

\section{References}

[1] "Buildings," European [Online]. Commission. Available: https://ec.europa.eu/energy/en/topics/energy-efficiency/buildings. [Accessed: 27-Oct-2017]. 
[2] L. Ratke, T. Welsch, M. Schnellenbach-Held, and B. Milow, "High performance aerogel concrete," High Tech Concr. Where Technol. Eng. Meet - Proc. 2017 fib Symp., no. October, pp. 117-124, 2017.

[3] A. Hermelink et al., "Towards nearly zero- energy buildings Definition of common principles under the EPBD," Eur. Comm., p. 467, 2013.

[4] M. Aegerter, N. Leventis, and M. Koebel, Aerogels handbook (Advances in Sol-Gel Derived Materials and Technologies). 2011.

[5] J. R. Heley, D. Jackson, and P. F. James, "Fine low density silica powders prepared by supercritical drying of gels derived from silicon tetrachloride," J. Non. Cryst. Solids, vol. 186, pp. 30-36, 1995.

[6] G. A. Nicolaon and S. J. Teichner, "Étude thermodynamique de l'adsorption d'argon et d'azote par les aérogels de silice," J. Chim. Phys. Physico-Chimie Biol., vol. 65, pp. 1480-1485, 1968.

[7] S. J. Teichner and G. A. Nicolaon, "Method of preparing inorganic aerogels," US 3672833, 1972.

[8] L. J. Tyler, "SILICA POWDERS," US 3015645, 1962.

[9] R.-M. Jansen and A. Zimmermann, "Process for the preparation of xerogels," US 5647962, 1997.

[10] S. W. Hwang, H. H. Jung, S. H. Hyun, and Y. S. Ahn, "Effective preparation of crack-free silica aerogels via ambient drying," J. Sol-Gel Sci. Technol., vol. 41, no. 2, pp. 139-146, 2007.

[11] S. W. Hwang, T. Y. Kim, and S. H. Hyun, "Effect of surface modification conditions on the synthesis of mesoporous crack-free silica aerogel monoliths from waterglass via ambientdrying," Microporous Mesoporous Mater., vol. 130, no. 1-3, pp. 295-302, 2010.

[12] C. J. Lee, G. S. Kim, and S. H. Hyun, "Synthesis of silica aerogels from waterglass via new modified ambient drying," J. Mater. Sci., vol. 37, no. 11, pp. 2237-2241, 2002.

[13] S. D. Bhagat, Y. H. Kim, K. H. Suh, Y. S. Ahn, J. G. Yeo, and J. H. Han, "Superhydrophobic silica aerogel powders with simultaneous surface modification, solvent exchange and sodium ion removal from hydrogels," Microporous Mesoporous Mater., vol. 112, no. 1-3, pp. 504-509, 2008.

[14] S. D. Bhagat, K. T. Park, Y. H. Kim, J. S. Kim, and J. H. Han, "A continuous production process for silica aerogel powders based on sodium silicate by fluidized bed drying of wet-gel slurry," Solid State Sci., vol. 10, no. 9, pp. 1113-1116, 2008.

[15] M. Torres-carrasco, J. G. Palomo, and F. Puertas, "Sodium silicate solutions from dissolution of glass wastes . Statistical analysis," Mater. construcción, vol. 64, no. 314, pp. 1-14, 2014.

[16] A. Stojanovic, M. Koebel, and B. E. Materials, "Low Cost Silica Aerogel Production," CISBAT 2015, pp. 27-32, 2015.

[17] T. Gerber, B. Himmel, and C. Hübert, "WAXS and SAXS investigation of structure formation of gels from sodium water glass," J. Non. Cryst. Solids, vol. 175, no. 2-3, pp. 160-168, 1994.

[18] A. Yoshida, "Silica Nucleation, Polymerization, and Growth Preparation of Monodispersed Sols," in The Colloid Chemistry of Silica, Advances in Chemistry, H. E. Bergna, Ed. Washington DC: American Chemical Society, 1994, pp. 51-62.

[19] B. Knoblich and T. Gerber, "Aggregation in $\mathrm{SiO} 2$ sols from sodium silicate solutions," J. Non. Cryst. Solids, vol. 283, no. 1-3, pp. 109-113, 2001.

[20] M.-S. Tsai, "The study of formation colloidal silica via sodium silicate," Mater. Sci. Eng. B, vol. 106, no. 1, pp. 52-55, 2004.

[21] R. K. Iler, The Chemistry of Silica. New York: Wiley-Interscience, 1979.

[22] S. Steiner, "Silica Aerogel." [Online]. Available: http://www.aerogel.org/?p=16. [Accessed: 19Dec-2017].

[23] H. M. Lim, J. Lee, J.-H. Jeong, S.-G. Oh, and S.-H. Lee, "Comparative Study of Various Preparation Methods of Colloidal Silica," Engineering, vol. 2, no. 12, pp. 998-1005, 2010.

[24] M. Koebel and S. Zhao, "Aerogels from Sodium Silicate - Towards Cost-Effective Mass Production Technologies," Bundesamt für Energ. BFE, 2012.

[25] S. S. Kistler, "Coherent Expanded-Aerogels," J. Phys. Chem., vol. 36, no. 1, pp. 52-64, 1931. 
[26] R. K. Iler, "Polymerization of polysilicic acid derived from 3.3 ratio sodium silicate," J. Phys. Chem., vol. 57, no. 6, pp. 604-607, 1953.

[27] A. L. G. Rees, "Directed Aggregation in Colloidal Systems and the Formation of Protein Fibers.," J. Phys. Chem., vol. 55, pp. 1340-1344, 1951.

[28] F. Schwertfeger, D. Frank, and M. Schmidt, "Hydrophobic waterglass based aerogels without solvent exchange or supercritical drying," J. Non. Cryst. Solids, vol. 225, pp. 24-29, 1998.

[29] P. J. Davis, C. Jeffrey Brinker, and D. M. Smith, "Pore structure evolution in silica gel during aging/drying I. Temporal and thermal aging," J. Non. Cryst. Solids, vol. 142, no. C, pp. 189-196, 1992.

[30] P. J. Davis, C. Jeffrey Brinker, D. M. Smith, and R. A. Assink, "Pore structure evolution in silica gel during aging/drying II. Effect of pore fluids," J. Non. Cryst. Solids, vol. 142, no. C, pp. 197207, 1992.

[31] R. Deshpande, D.-W. Hua, D. M. Smith, and C. J. Brinker, "Pore Structure Evolution in Silica Gel during Aging/Drying. III. Effects of Surface Tension," J. Non. Cryst. Solids, vol. 144, no. 1992, pp. 32-44, 1992.

[32] Y. C. Joung, M. J. Roh, J. C. Park, M. W. Kim, M. H. Lee, and C. S. Hahn, "Silica aerogel powder manufacturing system and processing method," EP2722311A2, 2014.

[33] S. Lee and M. J. Castaldi, "The effects of varied hydrogen chloride gas concentrations on corrosion rates of commercial tube alloys under simulated environment of WTE facilities," 16th Annu. North Am. Waste-to-Energy Conf., 2008.

[34] S. Brunauer, P. H. Emmett, and E. Teller, "Gases in Multimolecular Layers," J. Am. Chem. Soc., vol. 60, no. 1, pp. 309-319, 1938.

[35] E. P. Barrett, L. G. Joyner, and P. P. Halenda, "The Determination of Pore Volume and Area Distributions in Porous Substances. I. Computations from Nitrogen Isotherms," J. Am. Chem. Soc., vol. 73, no. 1, pp. 373-380, 1951.

[36] G. Reichenauer, "Structural Characterization of Aerogels," in Aerogels Handbook, New York: Springer, 2011.

[37] K. S. W. Sing, "Reporting physisorption data for gas/solid systems with special reference to the determination of surface area and porosity (Provisional)," Pure Appl. Chem., vol. 54, no. 11, 1982.

[38] G. S. Kim and S. H. Hyun, "Effect of mixing on thermal and mechanical properties of aerogelPVB composites," J. Mater. Sci., vol. 38, no. 9, pp. 1961-1966, 2003.

[39] M. D. F. Júlio and L. M. Ilharco, "Superhydrophobic hybrid aerogel powders from waterglass with distinctive applications," Microporous Mesoporous Mater., vol. 199, pp. 29-39, 2014.

[40] Aspen Aerogels, "Pyrogel ${ }^{\circledR}$ XTE," 2017. [Online]. Available: http://www.aerogel.com/productsand-solutions/pyrogel-xte/. [Accessed: 23-Dec-2017].

[41] L. Ratke, "Herstellung und Eigenschaften eines neuen Leichtbetons: Aerogelbeton," Beton- und Stahlbetonbau, vol. 103, no. 4, pp. 236-243, 2008.

[42] A. Parvathy Rao, A. Venkateswara Rao, G. M. Pajonk, and P. M. Shewale, "Effect of solvent exchanging process on the preparation of the hydrophobic silica aerogels by ambient pressure drying method using sodium silicate precursor," J. Mater. Sci., vol. 42, no. 20, pp. 8418-8425, 2007.

[43] A. P. Rao, A. V. Rao, and G. M. Pajonk, "Hydrophobic and physical properties of the ambient pressure dried silica aerogels with sodium silicate precursor using various surface modification agents," Appl. Surf. Sci., vol. 253, no. 14, pp. 6032-6040, 2007.

[44] A. P. Rao, A. V. Rao, and U. K. H. Bangi, "Low thermalconductive, transparent and hydrophobic ambient pressure dried silica aerogels with various preparation conditions using sodium silicate solutions," J. Sol-Gel Sci. Technol., vol. 47, no. 1, pp. 85-94, 2008.

[45] U. K. H. Bangi, A. V. Rao, and A. P. Rao, "A new route for preparation of sodium-silicate-based hydrophobic silica aerogels via ambient-pressure drying," Sci. Technol. Adv. Mater., vol. 9, no. 3, 2008. 
